\title{
Party and Cleavage in the 2016 Election
}

\author{
Jack Santucci* \\ Original: September 19, 2017 \\ This version: October 11, 2017
}

\begin{abstract}
I fit non-parametric spatial models to a novel set of survey data on the 2016 election $(\mathrm{N}=8,000)$. I find two underlying dimensions: "race/identity" and "trade-plus." Attitudes toward Muslim immigration and transgender people emerge as the clearest divides between Trump and Clinton voters. Trade is nearly orthogonal to "race/identity" and cleaves both candidates' blocs. Attitudes toward redistributive policies split both parties, depending on the question asked. Supporters of Republican and Democratic candidates reflect distinct positions on "race/identity" (except those of Kasich). Sanders supporters are at least as liberal as Clinton supporters on "race/identity." They are slightly to the left of all other candidates' supporters on "trade-plus." Compared to Sanders voters who voted for Clinton, Sanders voters who voted for Trump are more conservative on "race/identity" and slightly more liberal on "trade-plus."
\end{abstract}

Several recent analyses point to a public divided on matters of social tolerance. Sides (2017) shows that positions on immigration, religion, and race were more predictive of partisanship and vote choice in 2016 than they were in 2012. Griffin and Teixeira (2017) show that negative views of immigrants, Muslims, minorities, and feminists predict support for Donald Trump

*Independent scholar, Ph.D. Government, Georgetown University, jack@voteguy . com. Barak Hoffman and Andrew Vasile gave helpful comments. Any opinions, errors, and/or omissions are strictly those of the author. Raw data are from the Democracy Fund Voter Study Group and can be downloaded at https://www.voterstudygroup.org/ publications/2016-elections/data. THIS IS A WORKING DRAFT. 
in the primary and general elections. Ekins (2017) shows that attitudes toward Hillary Clinton and illegal and Muslim immigrants successfully classify Trump and non-Trump voters.

What about economics? Drutman (2017) finds that matters of rich versus poor have become less salient, allowing Donald Trump to win the support of economically liberal, socially conservative ex-Democrats. Ekins (2017) finds that perceptions about the economy separate Trump supporters from others. Notably, attitudes on trade had no apparent relationship to partisanship nor vote choice (Ekins 2017; Griffin and Teixeira 2017). Finally, according to McElwee and McDaniel (2017), "the current trajectory is towards a political system in which battles about class interest are obfuscated by a clash over the openness of society."

Taking Drutman's work as point of departure, this memo uses a different method to see what cleavages emerge from the same "VOTER Survey" data set that the other analysts used. I look at the same questions that Drutman's analysis included. Following Hare (2015), I make simple assumptions about survey responses, construct the data as one would construct a matrix of legislative roll calls, and fit a series of non-parametric spatial models.

This analysis recovers a two-dimensional ideological space that supports the above conjectures. The primary dimension can be called "race/identity conservatism," though it also captures immigration - consistent with Sides' observation about disagreement on what it means to be American. I call the second "trade-plus conservatism." The overall status of economics is debatable. A possible hedge is that it inherits elements of both dimensions.

Given the bitter primary fights in both parties, I also ask about the 2016 that might have been. Drutman's method found that Kasich voters were the "true moderates, caught in between the two parties on almost every issue, both economic and social." He also found that Cruz voters were notably conservative on both social and economic dimensions. I recover these findings. Interesting are those who voted for Sanders: not more conservative than Clinton voters on "race/identity," and somewhat more liberal on "trade-plus."

In sum, it is too soon to conclude with McElwee and McDaniel that our "trajectory" is toward a party system in which "a clash over the openness of society" overshadows traditional issues of rich versus poor. At a minimum, we would need similar, comparison data for 2012 and maybe 2020. That said, my findings are striking. I show clear polarization on the social dimension, then largely undifferentiated attitudes on trade-plus (except perhaps among 
Sanders supporters).

I want to stress that these results do not reflect the policy positions of the candidates. They cannot because the underlying data do not, since they came from a public opinion survey. Rather, this paper gives yet another picture of the 2016 electorate. Social issues trumped economics.

\section{A different approach to measuring cleavage}

Drutman selected a set of VOTER survey questions, sorted them into social and fiscal bins, rescaled the responses to fall between -1 and 1 , then computed an average on each dimension for each respondent. ${ }^{1}$ I take a different tack.

Rather than assign questions to issue dimensions ex ante, I let the dimensions emerge from a model of data. What I do is collapse the answers to each of Drutman's chosen questions into a binary $1 / 0$ response, then analyze the data in the way one might analyze Congressional roll calls.

In particular, I fit an optimal classification (OC) scaling algorithm to a "voting matrix" of binary survey responses (Poole 2000, 2005). ${ }^{2}$ I ask the computer for an answer in one, two, and three dimensions. Then I compare the fit of the models using Poole and Rosenthal's (1997) conventional measure, plus a measure derived by Roberts et al. (2015). Not only does OC let us construct an "ideal point" for each voter, thereby plotting them in $\mathrm{N}$-dimensional space. It also lets us see how specific issues map onto that space, e.g., what separates this group of people from that group of people. Finally, it tells us how well that issue separates people - whether it's a reliable classifier. $^{3}$

Is it okay to collapse the survey responses? That depends on how one thinks about choice in the face of a survey question. Models like OC assume the respondent will either take or leave a policy proposal (e.g., vote for the bill or stick with the status quo). I think this works for many survey questions. Consider the following question, designed to measure racial resentment:

1. This is basically a manual way to get NOMINATE-style results.

2. Armstrong et al. (2014) allude to a similar procedure in their textbook.

3. OC has several other advantages. Like all scaling methods, it frees us from subjectively coding the liberal/conservative character of an answer. Beyond that, it makes no assumptions about the utility function of a survey respondent - that is, how they weight proposals/alternatives and whether all people weight them the same. Rosenthal and Voeten (2004) make just this case for OC. 
Irish, Italian, Jewish, and many other minorities overcame prejudice and worked their way up. Blacks should do the same without any special favors.

- Strongly agree

- Agree

- Disagree

- Strongly disagree

- Don't know

The question implies a policy: "special favors." The implied alternative is "no special favors." Anyone who disagrees - weakly, strongly, whatever - thinks that blacks should not get special favors. Someone who (strongly) agrees thinks they should. And in saying "don't know" or skipping the question, the respondent literally abstains. ${ }^{4}$

\section{Advantage over regression \& cross-tabulation}

Many analyses of survey data begin with some dependent variable (e.g., general-election vote choice), then cross-tabulate by one or more chosen variables of interest. Multiple regression basically works the same way - pick some outcome; sequentially test predictors for strength of correlation.

The approach in this paper lets us process responses to a lot of survey questions at once. It also frees us from having to analyze different dependent variables in one-by-one fashion. Given data on outcomes of interest - including but not limited to primary- and general-election vote choice - we can see whether and to what extent a given attitude measure separates one outcome group from another. This allows us to find patterns that might otherwise take us a long time to find.

A disadvantage is that the results do not "account" for respondents' nonpolicy attributes. Including these attributes would strain the assumptions of the model. Consider a standard feeling thermometer question from the American National Election Study. ${ }^{5}$ It's not clear what policy proposal the respondent would be "taking or leaving" with their answer:

4. Following convention, yea $=1$, nay $=0$, and abstain $=9$.

5. Armstrong et al. (2014) do show, however, that it is possible to include such information by setting up pairwise comparisons. 
I'd like to get your feelings toward some of our political leaders and other people who are in the news these days. I'll read the name of a person and I'd like you to rate that person using something we call the feeling thermometer.

That said, should the scaling turn up questions that appear to divide people on some outcome of interest, we can include non-policy covariates in any subsequent regression-based analyses.

Overall, processing a lot of survey responses at once creates some space to avoid over-generalization. Anyone who read news in 2016 will remember one or more such "hot takes."

\section{Number and identity of dimensions}

I report two significant dimensions in the Drutman subset of VOTER data. One way to look at this is to compare the aggregate proportional reduction in error (APRE) from one-, two-, and three-dimensional models. APRE weights by the size of the "legislative minority" for the respective roll call. We weight because very lopsided roll calls will inflate our assessments of model fit. Table 1 shows that APRE improves by more than ten points when adding a second dimension. The rate of improvement drops to five points with the addition of a third dimension.

\begin{tabular}{ccc}
\hline Dims. & APRE & PCC \\
\hline 1 & 0.47 & 85.2 \\
2 & 0.58 & 88.4 \\
3 & 0.63 & 89.6 \\
\hline
\end{tabular}

Table 1: APRE and percentage of votes correctly classified (PCC) for OC in 1-3 dimensions.

The marginal proportional reduction in error (MPRE) may be a better tool for model selection. This is because APRE implicitly compares the current model to a null model (i.e., one in which we simply note the minority voted this way or that). MPRE directly compares the fit of two models (Roberts et al. 2015). Moving from a one- to two-dimensional model yields an MPRE of 0.21. Moving to three dimensions yields an additional gain 
of 0.11. In the absence of an accepted MPRE standard, I stick with the two-dimensional model.

Additional support for the two-dimensional model is found in a scree plot of eigenvalues from a spectral decomposition of the double-centered agreement score matrix (Figure 1). We see that dimensions in excess of two would not explain very many more "voting decisions." This is because there is a sharp elbow at two dimensions.

Two dimensions fit best.

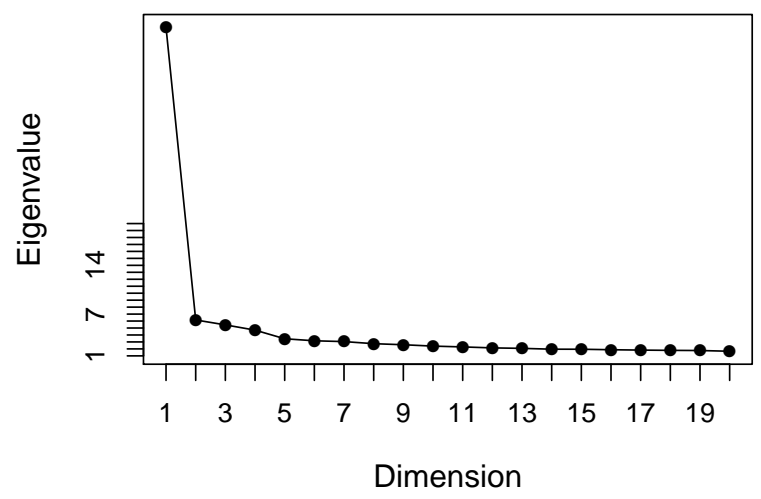

Figure 1: Scree plot indicating how many dimensions one ought to fit.

To understand what the dimensions mean, we can look at the "roll calls" defining them. One way to do this is to select $N$ roll calls with the highest PREs - that is, $N$ roll calls that classify very many respondents' choices correctly without doing so too easily. I set $N$ at 15 . Figure 2 plots survey respondents' ideal points in two dimensions, 15 cutting lines for our roll calls, and a word describing the survey question for each.

Social issues clearly define the first (horizontal) dimension. Several roll calls tapping anti-black resentment run vertically. These accompany questions on transgender rights and immigrants. The cutting line for a question on Muslims also runs top to bottom, except it tilts a bit at the top into the right of the space. Finally, a question on whether blacks need to work harder to overcome historical disadvantage is the "vote" second-best-fit by this model ( $\mathrm{PRE}=0.81,94$ percent correctly classified).

Interestingly, two questions tapping sexism do not register among the 


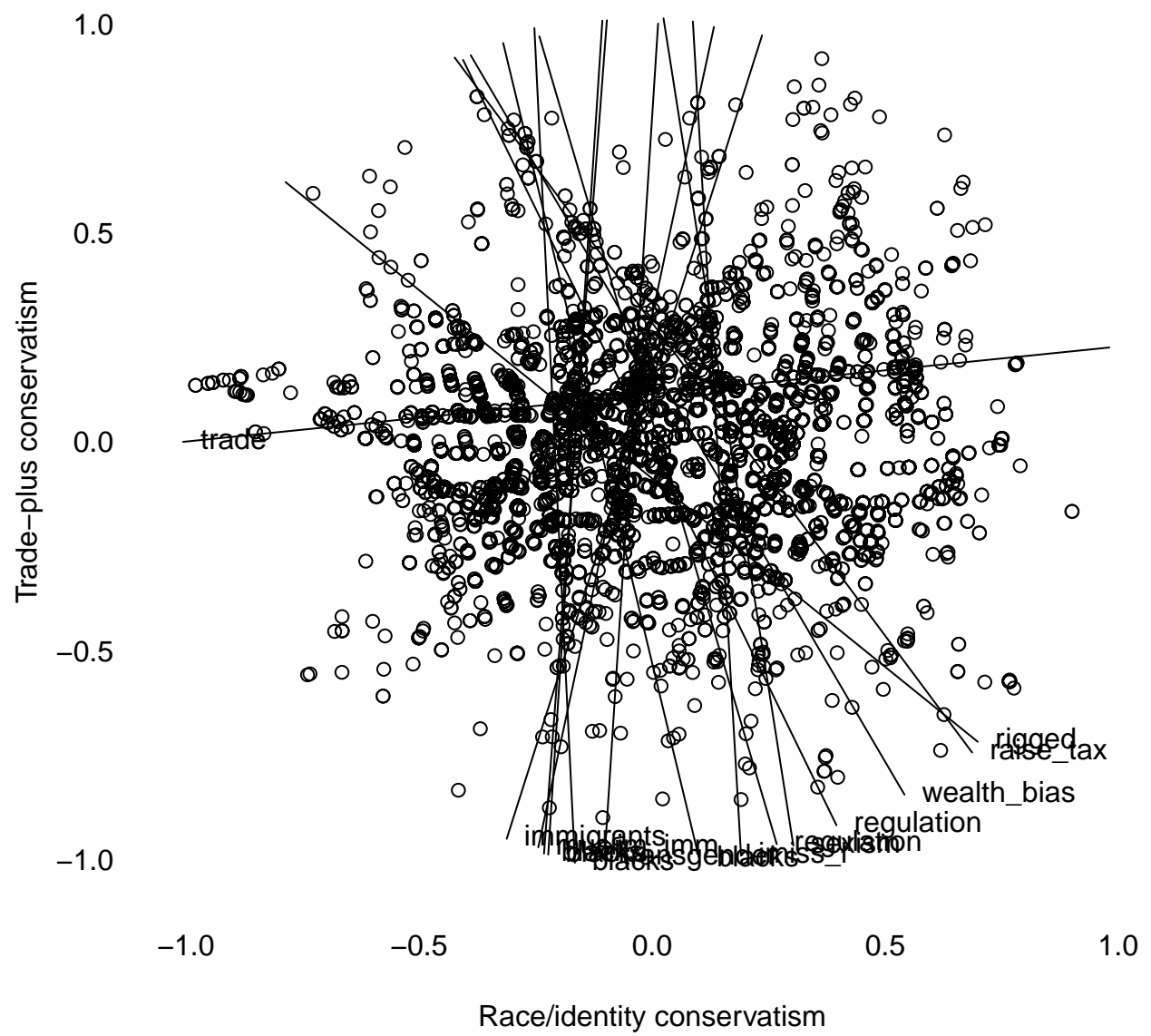

Figure 2: Ideal points and cutting lines for 15 best-fitting survey questions. 
top 15 best-fit votes. These rank at $22^{\text {nd }}$ and $24^{\text {th }}$ best-fit, with a correct classification of 86 percent each. I nonetheless include the better-fitting of these in the plots below ( $\mathrm{PRE}=0.63,86$ percent correctly classified).

Trade clearly has a big role in defining the second dimension. Note the nearly horizontal cutting line for free trade, which divides the top half of the plot from the bottom. Two such questions clock in with PREs of 0.71 and correct classifications of 92 and 93 percent.

The status of economics is less clear. As it turns out, the roll-call vote best fit by this model is one about whether "our economic system is biased in favor of the wealthiest Americans" ( $\mathrm{PRE}=0.82,93$ percent correctly classified). Its cutting line runs at a roughly 45-degree angle from the top-left to bottomright of the plot. Almost parallel are cutting lines for questions on taxing incomes in excess of $\$ 200,000(0.75,92 \%)$, the "rigged system" $(0.71,87 \%)$ and government economic intervention $(0.78,90 \%)$.

Why are the cutting lines for economics running diagonally? Poole and Rosenthal (1997) might say these votes reflect a trade-off between the dimensions. That is, some people may have thought that what's good for immigrants and minorities is bad for their economic well-being. Another interpretation might note that people are rejecting (or preferring) certain frames and slogans.

\section{A fuller look at the issues defining the space}

The preceding section interpreted the policy space strictly in terms of the 15 roll calls with the highest PRE values. What other questions were included? How do they map onto the party system of 2016 ?

Figure 3 plots the percentage of Clinton and Trump voters, respectively, "voting yea" on each of the 60 survey questions included in this analysis. Text labels give the names of the variables in the VOTER data set. Questions in the top left of the space represent policy positions favored by very many Trump and very few Clinton voters. In the bottom right, many Clinton and few Trump voters took the "yea" position.

Along the diagonal line segment, even numbers of voters in both blocs "voted yea." The closer one gets to the diagonal, the less a question tells us about voting in the general election. Questions at the top right of the space are especially interesting. These are points of bipartisan consensus in the sense that both blocs' voters take the respective policy positions. 


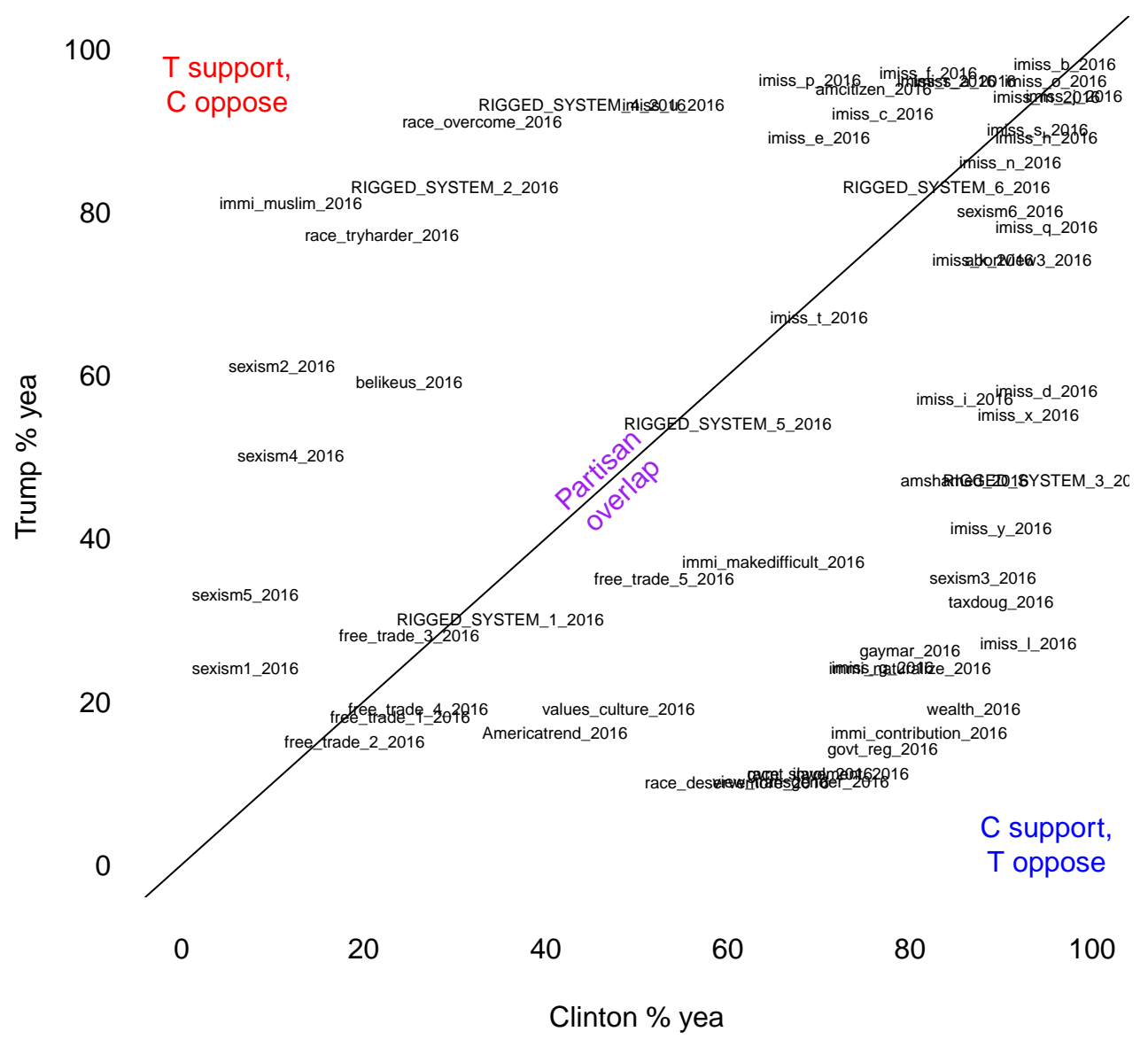

Figure 3: All 60 survey questions (with raw variable names) by the percentage of Clinton and Trump voters, respectively, "voting yea" on each. 


\section{Social positions predict vote choice}

Returning to ideal points, Figure 4 shows that two issues divide Trump and Clinton voters most clearly: views on transgender people and Muslim immigration. ${ }^{6}$ Graph tokens reflect reported vote choice. I have retained key cutting lines for blacks, transgender people, Muslims, trade, wealth bias, sexism, raising taxes, and rigged system. Interestingly, the Democrats are internally divided on the resentment question noted above about "special favors" for blacks.

Questions related to the wealth distribution come nowhere near as close to splitting the parties as trade, but there are internal divides. A question on whether the system is biased in favor of the wealthy cuts into Republican territory. At the same time, suggesting higher taxes on incomes over $\$ 200,000$ divides the Democrats internally.

\section{The primary contest}

Figure 5 replicates the foregoing two plots, shading points by reported primary vote. I leave it to the reader to interpret the result.

My next set of plots (Figure 6) is meant to investigate differences in attitudes among the different blocs of primary voters. With respect to the first dimension ("race/identity") we see clear differences between Clinton and Sanders voters, on the one hand, and the Republican candidates, on the other. Notably, however, Kasich supporters span the ideological range.

Results for the "trade-plus" dimension reflect fairly little differentiation. Sanders supporters are ever so slightly more liberal than all others. One way to look at this is to ask about the probability of seeing a Sanders supporter more liberal than a Clinton supporter on the second dimension. When looking at every possible match of Clinton and Sanders supporters, the probability of seeing a more liberal Sanders supporter is 0.62. (On the first dimension, that probability is 0.55 .)

6. Bivariate logit models imply the following probabilities of reporting a Trump vote, given an anti-Muslim or pro-transgender survey response, respectively: 0.78 and 0.11 . Muslim model: $\beta=3.37, \sigma=0.07, A I C=6307.2$. Transgender model: $\beta=-3.08$, $\sigma=0.07, A I C=6257.8$. 


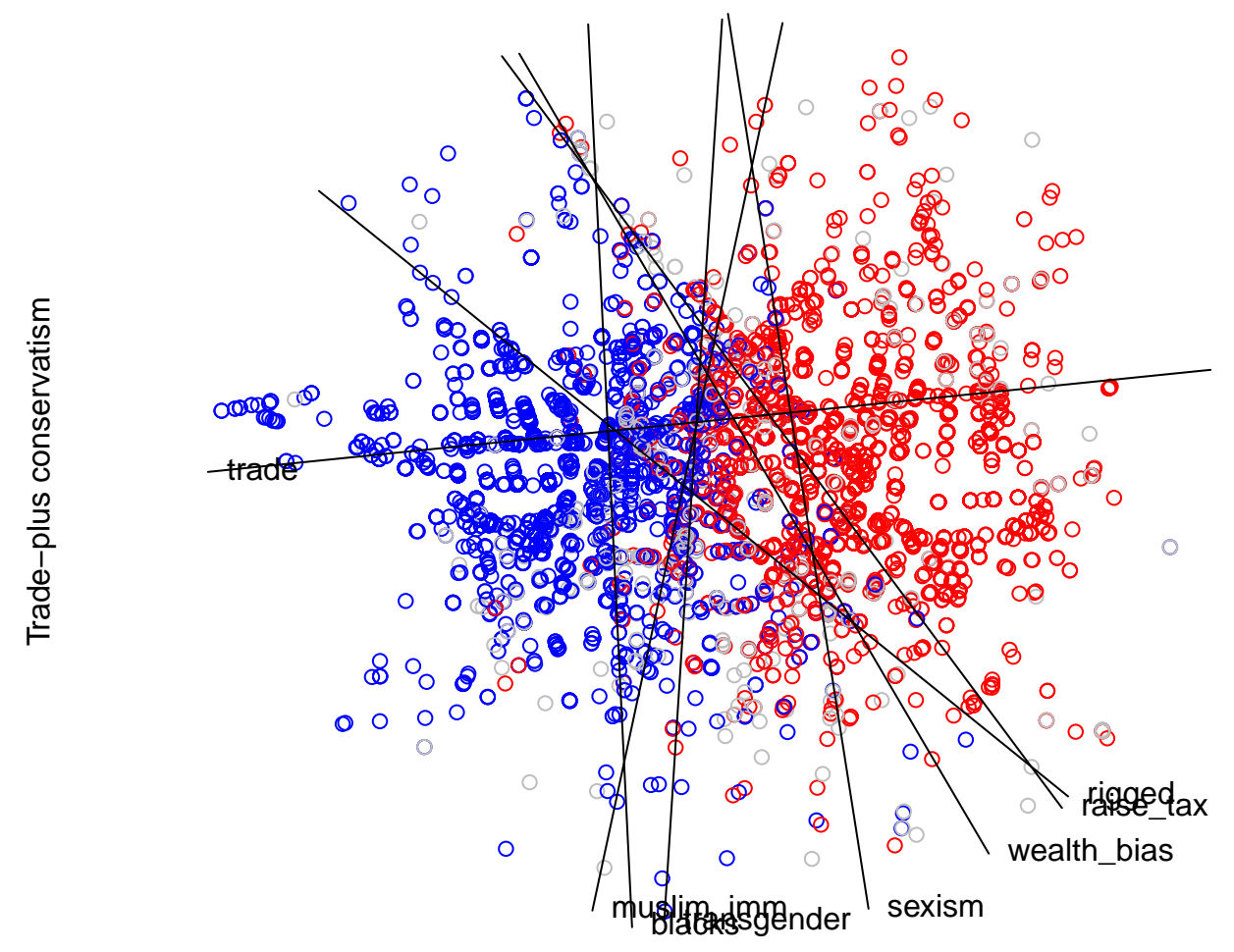

Race/identity conservatism

Figure 4: Ideal points by vote choice $($ blue $=$ Clinton, red $=$ Trump, gray $=$ other). 


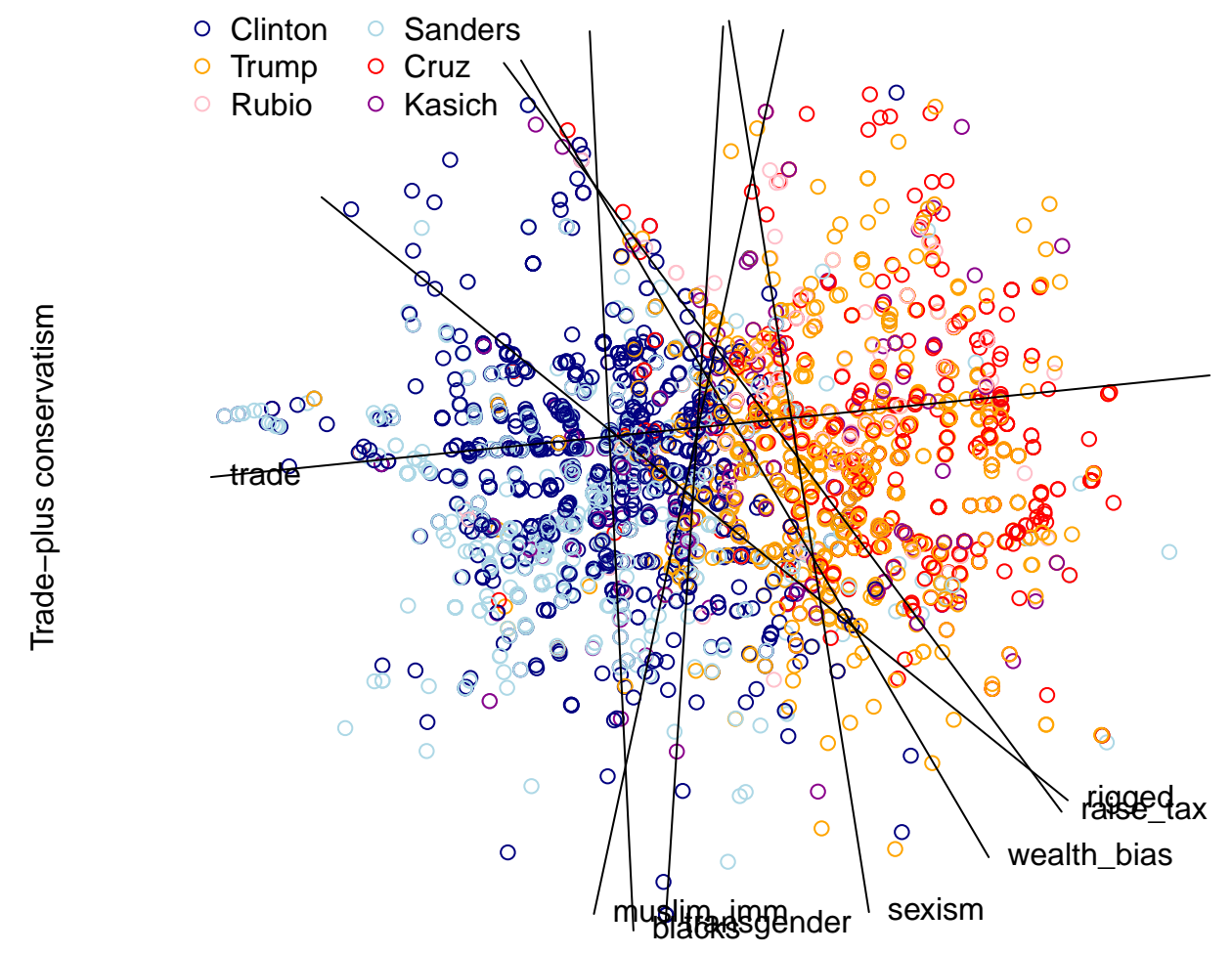

Race/identity conservatism

Figure 5: Ideal points by primary vote choice. 

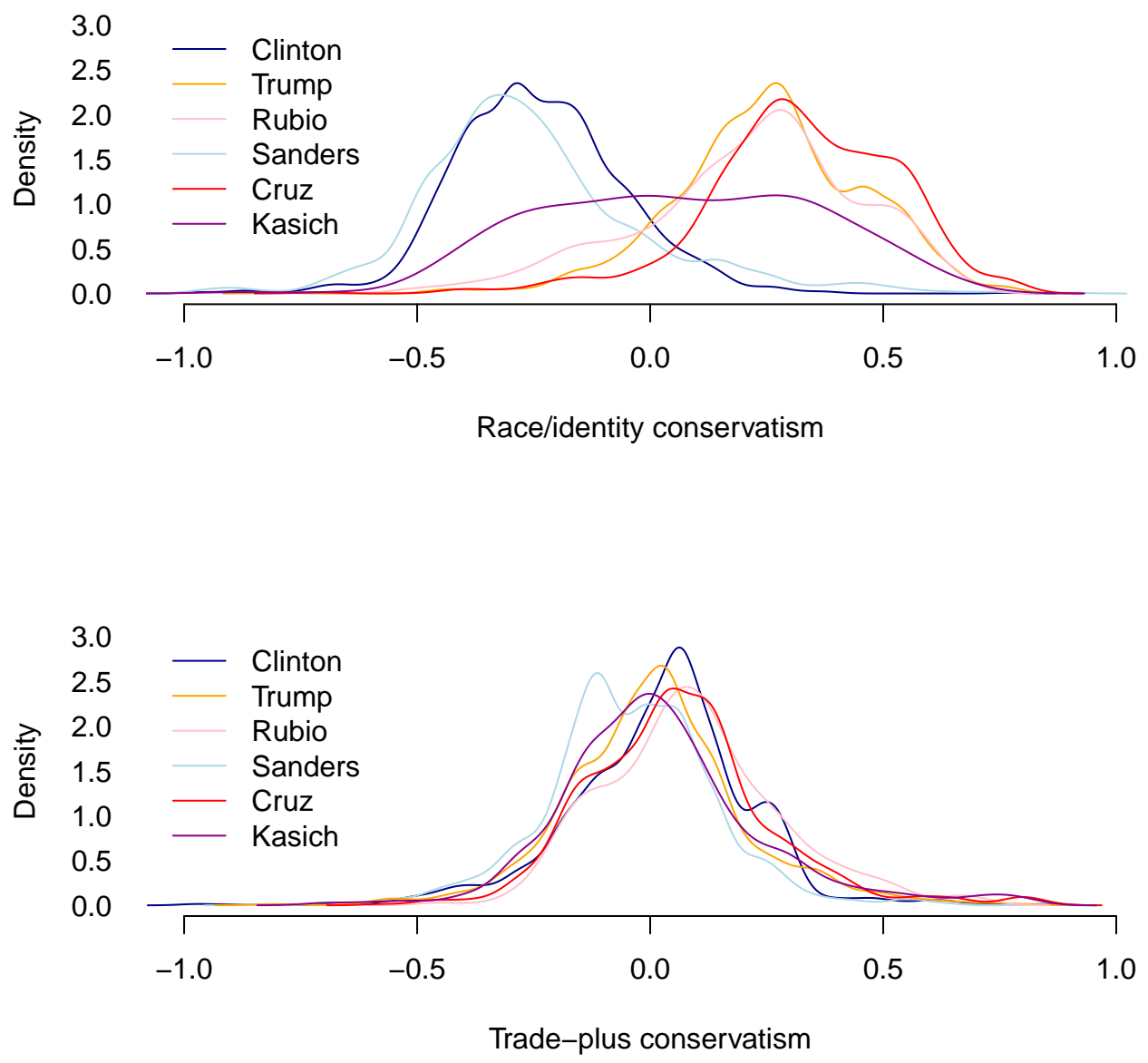

Figure 6: Density plots of ideal points on each dimension, by reported primary vote. 


\section{The Sanders-to-Trump voters}

What about those voters who went for Sanders in the primary, then voted for Trump in the general? Figure 7 plots the distributions of Sanders supporters' first- and second-dimension ideal points, conditional on whether they voted for Clinton or Trump in the general. We see that Sanders-to-Trump voters are clearly more conservative on "race/identity" and slightly less conservative on "trade-plus." The probability of a Sanders-to-Clinton voter being more liberal on the first dimension than a Sanders-to-Trump voter is 0.94. That probability on the second dimension is 0.47 . By a hair, Sanders voters who went to Trump were more liberal on "trade-plus."

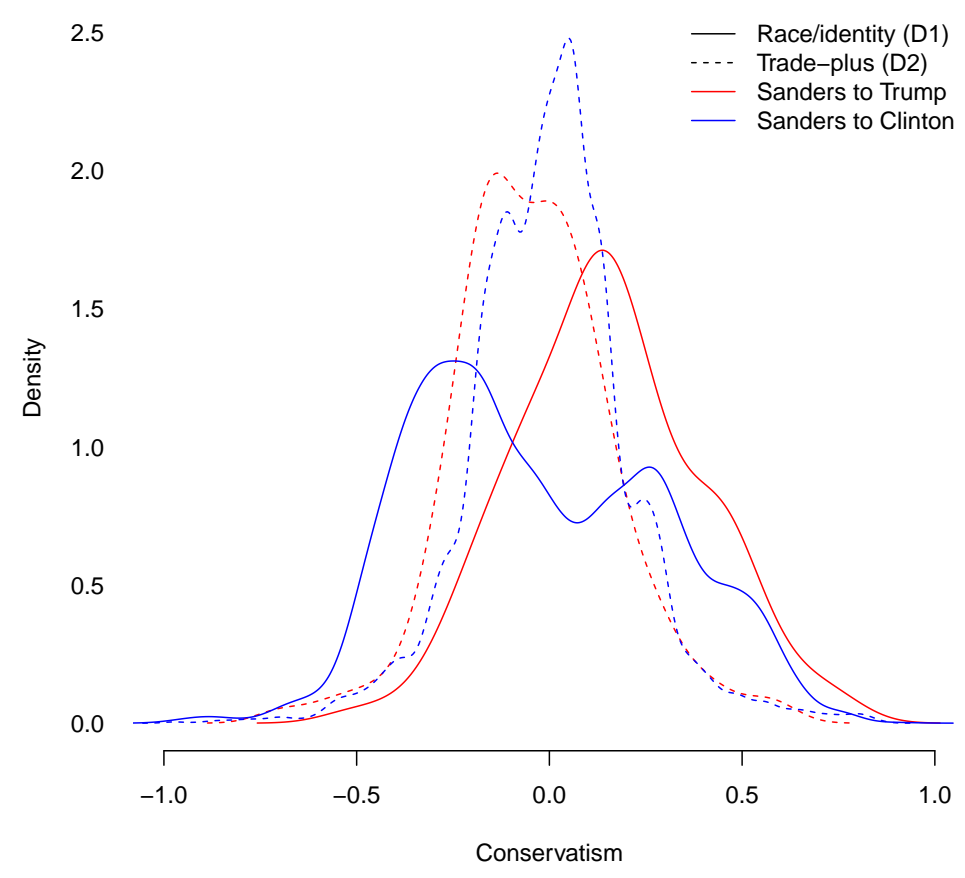

Figure 7: Distributions of ideal points on both dimensions for Sanders, conditional on voting for Clinton or Trump in the general. 


\section{Conclusion}

My goal has been to tackle some burning questions with a different method. Everything we know scientifically depends on our faith in the data, the model, the questions that were asked, and the unimportance of those that were not.

It is worth restating, however, that everything above is based on a survey of public opinion. Nor do we know whether voters were reacting to concrete policy proposals - or the value (for winning) of policy messages they heard in the campaign.

\section{References}

Armstrong, David A., Ryan Bakker, Royce Carroll, Christopher Hare, Keith T. Poole, and Howard Rosenthal. 2014. Analyzing Spatial Models of Choice and Judgment with R. Boca Raton, FL: Taylor \& Francis.

Drutman, Lee. 2017. Political Divisions in 2016 and Beyond: Tensions Between and Within the Two Parties. Research Report. Democracy Fund Voter Study Group.

Ekins, Emily. 2017. The Five Types of Trump Voters: Who They Are and What They Believe. Research Report. Democracy Fund Voter Study Group.

Griffin, Robert, and Ruy Teixeira. 2017. The Story of Trump's Appeal: A Portrait of Trump Voters. Research Report. Democracy Fund Voter Study Group.

Hare, Christopher. 2015. "Constrained Citizens? Ideology and the American Voter." Doctoral dissertation, University of Georgia.

McElwee, Sean, and Jason McDaniel. 2017. "Fear of Diversity Made People More Likely to Vote Trump." The Nation (March 14). Accessed September 18, 2017. https://www.thenation.com/article/fear-ofdiversity-made-people-more-likely-to-vote-trump/.

Poole, Keith T. 2000. "Nonparametric Unfolding of Binary Choice Data." Political Analysis 8 (3): 211-237.

- 2005. Spatial Models of Parliamentary Voting. New York: Cambridge University Press. 
Poole, Keith T., and Howard Rosenthal. 1997. Congress: A Political-Economic History of Roll Call Voting. New York, NY: Oxford University Press.

Roberts, Jason M., Steven S. Smith, and Stephen R. Haptonstahl. 2015. "The Dimensionality of Congressional Voting Reconsidered." American Politics Research (October 15). doi:10.1177/1532673X15608940.

Rosenthal, Howard, and Erik Voeten. 2004. "Analyzing Roll Calls with Perfect Spatial Voting: France 1946-1958." American Journal of Political Science 48, no. 3 (July): 620-632.

Sides, John. 2017. Race, Religion, and Immigration in 2016: How the Debate over American Identity Shaped the Election and What It Means for a Trump Presidency. Research Report. Democracy Fund Voter Study Group. 